\title{
Soybean Root Systems and Sudden Death Syndrome Severity: Taproot and Lateral Root Infection
}

\author{
Loretta M. Ortiz-Ribbing and Darin M. Eastburn, USDA-ARS and the Department of Crop Sciences, University \\ of Illinois, Urbana 61801
}

\begin{abstract}
Ortiz-Ribbing, L. M., and Eastburn, D. M. 2004. Soybean root systems and sudden death syndrome severity: Taproot and lateral root infection. Plant Dis. 88:1011-1016.

Experiments were conducted in the greenhouse to evaluate the role that infection location (taproot versus lateral root) plays in disease development of sudden death syndrome (SDS) on soybean (Glycine max) caused by the fungus Fusarium solani f. sp. glycines. Root characteristics of 12 soybean cultivars, representing a range of SDS reactions, were evaluated and compared for disease responses. A method was developed to facilitate taproot or lateral root infection. Results show that this procedure may be useful for observing a continuum of foliar and root disease responses. Significant differences in root length, surface area, and average diameter were observed among cultivars when infection occurred at the taproot or on the lateral roots. A significant correlation existed between foliar symptoms (i.e., area under the disease progress curve [AUDPC]) and root length, surface area, and volume for inoculated plants. Root volume and percent root discoloration were significantly different among individual soybean cultivars, and percent root discoloration was associated with AUDPC values only when the initial site of infection was on the lateral roots of soybean plants. Useful information about root system responses to SDS may be obtained from infection of the entire root system as opposed to only taproot infection.
\end{abstract}

Additional keywords: digital imaging, Fusarium virguliforme, greenhouse assay, WinRhizo

Sudden death syndrome (SDS) of soybean (Glycine max (L.) Merr.) is caused by the fungal organism Fusarium solani (Mart.) Sacc. f. sp. glycines (22). Aoki et al. (1) have recently shown that SDS is caused by two distinct species within the Fusarium solani complex and have proposed a name change (Fusarium virguliforme O'Donnell \& T. Aoki) for the organism causing SDS in North America. However, because this name change has yet to be fully accepted, in this paper, we will continue to refer to $F$. solani $\mathrm{f}$. $\mathrm{sp}$. glycines as the SDS pathogen.

Screening soybean plants for resistance to $F$. solani $\mathrm{f}$. sp. glycines currently relies heavily on the severity of foliar symptoms as an indication of plant resistance $(7,10-$ 13,16,17,24-26,29). Foliar screening studies do not typically involve the evaluation of the root systems, and foliar disease severity ratings do not always correlate well with soybean yield, especially when SDS disease severity is moderate to low $(8,9,34)$. Njiti et al. (20) illustrated that the severity of soybean root rot caused by $F$.

Corresponding author: D. M. Eastburn

E-mail: eastburn@uiuc.edu

Accepted for publication 5 May 2004.

Publication no. D-2004-0625-02R

(C) 2004 The American Phytopathological Society solani f. sp. glycines was important and should be used in combination with foliar symptom severity as an indication of SDS resistance in soybean.

The presence of this fungus on the lateral roots of soybean plants appears to be an important aspect affecting the development of SDS. Rupe (24) isolated F. solani from soybean lateral root sections, epidermal and cortical sections of the taproot, and lower stem sections. The highest frequency $(23 \%)$ of isolation was from the epidermis of the taproot. The frequency of infection on the lateral roots was $19 \%$. Since most of the soybean root system consists of lateral roots that emerge from the top 10 to $15 \mathrm{~cm}$ of the taproot and spread horizontally in the upper $10 \mathrm{~cm}$ of soil (18), SDS most likely results from pathogen infection on portions of the root system that randomly encounter the fungus in the upper $15 \mathrm{~cm}$ of soil (27). Gray and Achenbach (5) also illustrated that the soil inoculum level of $F$. solani impacted root rot severity, and at high inoculum levels, a greater percentage of lateral and taproots became necrotic. Overall, studies have illustrated the prevalence of the fungus on both lateral roots and taproots; yet a comparison between taproot and lateral root infection has not been made.

Current assays used to study SDS depend on easy and reliable methods for infecting taproots $(6,7,10,11,15,17,19,20$, 24,29-31). Screening work $(6,7,19)$ has demonstrated that most soybean cultivars are susceptible to SDS and develop severe foliar symptoms after taproots are infected in the seedling stage. However, the range of root and foliar symptoms is not clearly defined, as current assays usually expose young seedlings to high doses of inoculum in order to guarantee a response. In addition, assays based on foliar symptoms resulting from taproot infection may not provide the best evaluation of root system resistance. A greenhouse assay that provides a continuum of disease responses, and includes evaluation of root system characteristics, might provide a better assessment of resistance.

It has been shown that a range of resistance/susceptibility reactions to SDS exists among soybean cultivars $(7,17,26,30)$, and that root resistance to $F$. solani f. sp. glycines exists $(16,17,20)$. It is not known whether physical characteristics of the soybean root system (root length, volume, surface area, and average diameter) enable the soybean plant to resist colonization or overcome the effects of infection. Overall, the role of roots in the development of SDS is not well documented.

The objectives of this study were to: (i) determine whether root characteristics (length, surface area, volume, and average diameter) are correlated with SDS resistance levels of 12 commercial soybean cultivars, (ii) illustrate whether location (taproot versus lateral roots) of infection impacts SDS development, and (iii) develop an assay that provides a continuum of foliar and root disease responses that can be used in screening soybean plants for resistance to SDS.

\section{MATERIALS AND METHODS}

Inoculum placement and planting. Two trials of an inoculum placement assay were initiated in the greenhouse on 21 September and 7 December 2001. In each trial, soybean plants were grown in the greenhouse in white, polypropylene 947 $\mathrm{ml}$ pots, measuring $14 \mathrm{~cm}$ tall, with an upper lip measuring $10.2 \mathrm{~cm}$ diameter tapering down to $8.2 \mathrm{~cm}$ diameter at the bottom. Four holes were drilled in the bottom of each pot for drainage. Pots were filled with a steam-pasteurized, Torpedo sand:soil (2:1) mix. The soil for the mix belonged to the Drummer/Flanagan soil series. The $\mathrm{pH}$ values for the sand and soil were approximately 6.1 and 5.8, respectively. Soil was mixed with the pathogen 1 
day prior to planting at a rate of $40 \mathrm{ml}$ of ground sorghum (Sorghum bicolor (L.) Moench) inoculum to $4.5 \mathrm{~kg}$ of soil, which resulted in an inoculum concentration of approximately $10,000 \mathrm{CFU} / \mathrm{g}$ of soil. The Monticello isolate (Mont-1) of $F$. solani f. sp. glycines $(6,10,19)$ was grown on sorghum in the lab under sterile conditions following the procedure of Hartman et al. (6). Prior to mixing with the soil, the colonized sorghum seed was dried and ground using a Reitz Disintegrator (Rietz Co., Westchester, PA) with a 3/32-mesh screen that produced a coarse flour.

Black plastic tubes $(4 \mathrm{~cm}$ diameter and $15 \mathrm{~cm}$ long) were used to separate each pot into a central inner (taproot) core and an outer (lateral root) region during the planting phase. One tube was used for each treatment to avoid contamination during planting. A layer of noninfested, pasteurized soil, approximately $1.3 \mathrm{~cm}$ in depth, filled the bottom of each pot to prevent cross-contamination of the inner core and the outer region during planting. The tube opening was covered with a plastic beaker and centered in the pot before approximately $990 \mathrm{~g}$ of infested or noninfested soil was carefully added to the outer region around the tube. The beaker cover was removed from the tube, and a funnel was used to fill the tube with approximately $140 \mathrm{~g}$ of infested or noninfested soil, taking care not to let any soil fall into the outer area of the pot. When the soil was in place, the tube was gently pulled up and out of the pot. Two soybean seeds were planted to a depth of $1.3 \mathrm{~cm}$ in the center core area of the pot. Seeds were covered with $1.3 \mathrm{~cm}$ of noninfested soil. Twelve SDS-susceptible and -resistant soybean cultivars, representing maturity groups 2.9 to 3.7 , were used based on commercial availability and on suggestions from seed companies (Table 1).

Pots were arranged in a completely randomized design on a greenhouse bench under 1,000-W high-pressure, sodium vapor lights $\left(156 \mu \mathrm{E} \cdot \mathrm{s}^{-1} \cdot \mathrm{m}^{-2}\right)$ providing 16 $\mathrm{h}$ of daylight. Temperature was maintained at $25 \pm 3^{\circ} \mathrm{C}$ during the day and $22 \pm 3^{\circ} \mathrm{C}$ for the 8-h dark period. Plants were watered as necessary to maintain adequate soil moisture. Spacing of the pots on the bench and a layer of noninfested soil covering the seeds prevented movement of the pathogen from splashing soil during overhead watering. Plants were thinned to one per pot after emergence. Treatments for the inoculum placement assay were: (i) noninfested soil in both the inner core and outer region (control 1), (ii) infested soil in the inner core with noninfested soil in the outer region to promote taproot infection (inner core), (iii) noninfested soil in the inner core with infested soil in the outer region, to promote lateral root infection (outer region), and (iv) noncolonized ground sorghum mixed with soil in the outer region with the inner core filled with noninfested soil (control 2). Each treatment in each trial had five replicates per cultivar. Each trial ended 30 days after planting.

A preliminary inoculum placement assay was conducted using an inoculum rate of $80 \mathrm{ml}$ per $4.5 \mathrm{~kg}$ of soil. This experiment used the previously described procedure for mixing soil and filling pots, and included the treatments mentioned above. It also included an additional control treatment with infested ground sorghum mixed with soil in the inner core and noninfested soil in the outer region.

Foliar and root ratings. Beginning about 2 weeks after planting, foliar disease severity was evaluated on five dates, every 3 to 4 days, after disease symptoms appeared. Foliar symptom severity was rated using a modified 0 to 5 scale from Hartman et al. (6): $0=$ no symptoms; $1=1$ to $10 \%$ of foliage with light symptoms, mottling or mosaic patterns on leaves; $2=11$ to $30 \%$ of foliage with symptoms, moderate interveinal chlorosis and necrosis; $3=$ 31 to $70 \%$ of foliage with symptoms, heavy interveinal chlorosis and necrosis; 4 $=71$ to $90 \%$ of foliage with symptoms, severe interveinal chlorosis and necrosis; 5 $=91$ to $100 \%$, dead plants with no foliage.

Table 1. Soybean cultivars used in Fusarium solani f. sp. glycines inoculum placement trials

\begin{tabular}{lccl}
\hline Soybean cultivar & Brand $^{\mathbf{a}}$ & Maturity group & Company SDS $^{\mathbf{b}}$ rating \\
\hline D370RR & Garst & 3.7 & $1.5^{\mathrm{c}}$, "Excellent field tolerance" \\
D355RR & Garst & 3.5 & $2^{\mathrm{c}}$ \\
D308 & Garst & 3.0 & Susceptible \\
D354RR/N & Garst & 3.5 & $3.4^{\mathrm{c}}$, susceptible \\
372 & Lewis & 3.7 & "Good SDS tolerance" \\
$3552 \mathrm{RR}$ & Lewis & 3.5 & Susceptible \\
$3556 \mathrm{STS}$ & Lewis & 3.5 & Susceptible \\
92B91 & Pioneer & 2.9 & $8^{\mathrm{d}}$ \\
9306 & Pioneer & 3.0 & $8^{\mathrm{d}}$ \\
9363 & Pioneer & 3.6 & $3^{\mathrm{d}}$ \\
$3687 \mathrm{RR}$ & Trisoy & 3.6 & "Excellent SDS rating" \\
3252 & Trisoy & 3.2 & Susceptible \\
\hline
\end{tabular}

a Brands are from the following seed companies: Garst Seed Company, Lewis Hybrids, Inc., Trisler Seed Farms, Inc., and Pioneer Hi-Bred International, Inc.

${ }^{\mathrm{b}}$ Sudden death syndrome.

${ }^{\mathrm{c}}$ Garst Seed Company SDS rating scale: $1=$ excellent, 5 = poor.

${ }^{d}$ Pioneer Hi-Bred International SDS rating scale: $1=$ poor, $9=$ excellent
Foliar ratings were converted to percentages using the midpoint rule (3), and the severity value for each rating category was used to calculate area under the disease progress curve (AUDPC). Because cultivar maturity groups differed, it was decided that AUDPC values would represent disease severity better than severity at a single rating date. AUDPC was calculated using the formula:

$$
\mathrm{AUDPC}=\sum_{i=1}^{n-1}\left[\left(X_{i+1}+X_{i}\right) / 2\right]\left(t_{i+1}-t_{i}\right)
$$

in which $X_{i}=$ percent foliar symptom severity at the $i$ th observation, $t_{i}=$ time (days between ratings) for the $i$ th observation, and $\mathrm{n}=$ total number of observations $(\mathrm{n}=$ 5) (33). Root systems were visually rated immediately after washing by recording the percentage of the root system showing discoloration.

Digital imaging. The upper vegetative portion of the soybean plant was removed just above the uppermost lateral root. Digital root images were acquired with the use of a flatbed scanner (Regent Instruments LA1600, Epson model EU-22) and analyzed using WinRhizo (Ver. 5.0A; Regent Instruments, Quebec, Canada) root analysis software. This method calculated morphological root measurements based on Tennant's (32) statistical line intersect method. Root systems, placed in clear plastic trays and immersed in water, were scanned at 400 dpi with a pixel size of $0.063 \mathrm{~mm}$. Using the automatic Tennant method, all root images were analyzed for root length, volume, surface area, and average diameter (21).

Movement in soil. An assay was conducted to determine whether the fungus moved within the pots between the infested inner core and the noninfested outer region, or from the infested outer region to the noninfested inner core, during the course of the experiment. The study was repeated three times with three replications. Pots were filled with infested soil in the same manner and using the same treatments described above. A round, plastic stick was inserted into the center of the inner core to mark the center for soil sampling. Treatments were the same as previously described, but soybean seeds were not planted in these pots in order to facilitate removing soil samples. Pots were arranged in a completely randomized design on a greenhouse bench under the lighting and temperature regime previously described. The pots of soil were watered as necessary to maintain adequate soil moisture, using the same watering regime as the assay for plants described previously.

Soil samples were collected 3 days after potting and again 22 to 24 days after potting. A no. 6-diameter cork borer was used to take one soil sample from the inner core area (marked by the plastic inserted stick), and one from the center of the outer region of each pot. Cork borers were washed and 
disinfested with 70\% ethyl alcohol between samples. Soil was allowed to dry for 24 to $72 \mathrm{~h}$. The presence of the pathogen from soil was determined using the dilution and modified plating procedure from Rupe et al. (27). Plates were incubated at room temperature, and $F$. solani f. sp. glycines colonies were counted after 7 days. Soil dilutions were plated onto a semiselective medium modified from Rupe et al. (27). The modified medium consisted of 1 $\mathrm{g}$ of $\mathrm{KH}_{2} \mathrm{PO}_{4}, 1 \mathrm{~g}$ of $\mathrm{MgSO}_{4} \cdot \mathrm{H}_{2} \mathrm{O}, 0.5 \mathrm{~g}$ of $\mathrm{KNO}_{3}, 20 \mathrm{~g}$ of sucrose, $20 \mathrm{~g}$ of Difco Bacto Agar (Becton, Dickinson and Company, Sparks, MD), and 1 liter of distilled deionized water. After autoclaving and cooling to $60^{\circ} \mathrm{C}, \mathrm{pH}$ was adjusted to 4.5 using $85 \%$ lactic acid, and $0.25 \mathrm{~g}$ of pentachloronitrobenzene (PCNB), $0.10 \mathrm{~g}$ of chlorotetracycline, $0.30 \mathrm{~g}$ of streptomycin, $0.10 \mathrm{~g}$ of neomycin, and $0.05 \mathrm{~g}$ of rifampicin were added and mixed thoroughly before pouring. Rifampicin and PCNB were dissolved in $1 \mathrm{ml}$ and $10 \mathrm{ml}$ of $95 \%$ ethyl alcohol, respectively.

Verification of fungal movement in root systems. Two trials of an experiment were conducted to verify movement of the fungus from lateral roots to the main taproot. Plants were grown using the previously described protocol, except that only three Lewis cultivars (3552RR, 3556STS, and 372) were used.

Cross-sections of five roots were cut from two positions from each plant's root system. Root locations were the main taproot (uppermost part of the taproot, just below the soil line) and lateral roots (five randomly selected sections, beyond the diameter of the inner core). Root crosssections were washed thoroughly with water, surface-sterilized with $0.5 \%$ sodium hypochlorite for $2 \mathrm{~min}$, rinsed in sterile double-distilled water, and dried on a sterile paper towel prior to plating. The root crosssections were placed on the semiselective medium, previously described, and incubated at $24^{\circ} \mathrm{C}$ for 7 days. The incidence of blue colored colonies of $F$. solani $\mathrm{f}$. sp. glycines in each root cross-section was counted, and macroconidia of the fungus were identified microscopically (23).

Data analysis. Both trials of the inoculum placement assay were analyzed using a two-way analysis of variance and covariance. Data were analyzed using Proc MIXED of SAS (SAS Version 8.01, SAS Institute, Cary, NC). Location of the inoculum in the soil (inner core, outer region, control) and the 12 soybean cultivars were designated as the fixed main effects. Repeated trials and the trial by inoculum treatment interaction were designated as random effects. The experimental unit was the individual soybean plant. Fisher's protected least significant difference (LSD, $P$ $\leq 0.05)$ was used to compare root characteristic differences among cultivars. The CORR procedure of SAS was used to compute correlation coefficients (Pearson) between the root variables length, surface area, volume, average diameter, discoloration, and AUDPC. The univariate procedure of SAS was used to determine that residual error terms for root discoloration data were normally distributed; therefore, percentages were not transformed for use in statistical analysis. The verification of fungal movement assays were analyzed using Proc GLM of SAS.

\section{RESULTS}

Inoculum placement. In the preliminary inoculum placement assay, using 80 $\mathrm{ml}$ of inoculum per $4.5 \mathrm{~kg}$ of soil, soybean roots growing in pots containing soil plus noncolonized ground sorghum in the outer region were discolored. In subsequent trials using $40 \mathrm{ml}$ of inoculum per $4.5 \mathrm{~kg}$ of soil, no root discoloration was observed on soybean roots in the noncolonized sorghum control treatment; therefore, this treatment was not included in the results.

When infested treatments (i.e., inner core and outer region) were combined, root length, surface area, and volume for inoculated roots showed a significant $(P<$ $0.0001)$ negative correlation $(r=-0.61$, -0.62 , and -0.60 , respectively) with AUDPC values, but there was no correlation between percent root discoloration and AUDPC.

When inoculation treatments were analyzed separately, root characteristics of plants grown in pots with an infested outer region showed a significant positive correlation between the percent root discoloration rating and AUDPC values (Table 2). However, plants grown in pots with the inner core containing infested soil showed no significant correlation between AUDPC values and root discoloration ratings. In addition, AUDPC was negatively correlated with root length, surface area, and volume for both treatments, but there was no correlation between AUDPC and average root diameter. In both infested soil treatments, there was a significant negative correlation between root discoloration and root length, surface area, and volume. However, a significant positive association existed between root discoloration and average root diameter. Root characteristics for plants grown in pots with an infested outer region were more highly correlated with root discoloration and AUDPC than were root characteristics for plants grown in pots with an infested inner core.

All soybean cultivars, except Pioneer Variety 9306, Garst D370RR, and Trisoy 3252, had significantly $(P \leq 0.10)$ higher AUDPC values when inner core soil was infested with $F$. solani f. sp. glycines, indicating a greater amount of foliar disease symptoms from taproot infection (Table 3). Significant differences in root discoloration were only seen among cultivars when lateral roots were inoculated (outer region).

The 12 cultivars grown in the noninfested control pots had similar root lengths and surface areas (Table 4), but significant differences in average root diameter and volume were observed (Table 5). Root length, surface area, and volume for all cultivars were significantly greater for noninoculated plants than for those grown in either infested soil treatment. No significant differences in root length, surface area, volume, and average diameter were observed among the individual cultivars between each of the infested soil treatments (Tables 4 and 5). Significant cultivar differences in volume of roots were observed only when the outer soil region was infested.

Of the 12 cultivars, some showed a differential response to infection by the

Table 2. Pearson correlation coefficients for root characteristics and area under the disease progress curve (AUDPC) values of soybean plants grown in pots with the outer region soil or the inner core infested with Fusarium solani f. sp. glycines

\begin{tabular}{lccccc}
\hline & \multicolumn{2}{c}{ Outer region $^{\mathbf{a}}$} & & \multicolumn{2}{c}{ Inner core $^{\mathbf{a}}$} \\
\cline { 2 - 3 } \cline { 5 - 6 } Root characteristic & $\begin{array}{c}\text { Root discoloration }^{\mathbf{b}} \\
\mathbf{( \% )}\end{array}$ & $\begin{array}{c}\text { Foliar } \\
\text { AUDPC }\end{array}$ & & $\begin{array}{c}\text { Root discoloration } \\
(\%)\end{array}$ & $\begin{array}{c}\text { Foliar }^{\mathbf{\%}} \\
\text { AUDPC }\end{array}$ \\
\hline Root length & -0.69 & -0.49 & & -0.50 & -0.43 \\
$(\mathrm{~cm})$ & $(0.0001)^{\mathrm{d}}$ & $(0.0001)$ & & $(0.0001)$ & $(0.0001)$ \\
Root surface area & -0.67 & -0.49 & & -0.54 & -0.39 \\
$\left(\mathrm{~cm}^{2}\right)$ & $(0.0001)$ & $(0.0001)$ & & $(0.0001)$ & $(0.0001)$ \\
Average root & 0.42 & 0.16 & & 0.19 & 0.13 \\
diameter $(\mathrm{mm})$ & $(0.0001)$ & $(0.089)$ & & $(0.04)$ & $(0.165)$ \\
Root volume & -0.60 & -0.46 & & -0.55 & -0.33 \\
$\left(\mathrm{~cm}^{3}\right)$ & $(0.0001)$ & $(0.0001)$ & & $(0.0001)$ & $(0.0002)$ \\
Root discoloration & & 0.37 & & & -0.18 \\
$(\%)$ & & $(0.0001)$ & & & $(0.054)$ \\
\hline
\end{tabular}

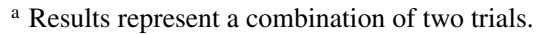

${ }^{\mathrm{b}}$ Root discoloration was rated visually as the percentage of root system showing discoloration.

${ }^{\mathrm{c}}$ Foliar ratings were converted to percentages, using the midpoint rule, and the foliar severity value for each rating category was used to calculate AUDPC using: AUDPC $=\sum_{i=1}^{n-1}\left[\left(X_{i+1}+X_{i}\right) / 2\right]\left(t_{i+1}-t_{i}\right)$ in which $X_{i}=$ the percent foliar symptom severity at the $i$ th observation, $t_{i}=$ time (days between ratings) at the $i$ th observation, and $\mathrm{n}=$ the total number of observations $(\mathrm{n}=5)$.

${ }^{d}$ Values in parentheses are the significance probabilities of the correlation. 
pathogen and a response to the location of infection, while other cultivars did not (Tables 4 and 5). For example, Lewis 3552RR and Lewis 3556STS (commercially rated as susceptible), which had similar maturity group ratings, showed no significant differences in root length, surface area, volume, or average diameter when grown in the noninfested control pots. When either the taproot (inner core) or lateral roots (outer region) were inoculated with the pathogen, root length and surface area were significantly lower for Lewis 3552RR than for Lewis 3556STS. Lewis $3552 \mathrm{RR}$ had a significantly greater average root diameter than Lewis 3556STS when the inner core (taproot) was infested, but no differences in root diameter between cultivars were observed when the outer region was infested. Root volume was significantly lower for Lewis 3552RR than for Lewis 3556STS when the lateral roots (outer region) were infected, but both cultivars had a similar volume of roots when the inner core was infested. Trisoy 3687RR and Trisoy 3252 had similar root lengths, surface areas, and volumes in untreated control plants. Root length and surface areas were significantly lower for Trisoy 3687RR plants than for Trisoy 3252 when the inner core was infested. No significant difference in root length or surface area was observed between these cultivars when the lateral roots (outer region) were inoculated, although root volume for Trisoy 3687RR was significantly higher than for Trisoy 3252 when the lateral roots were inoculated. Pioneer Variety 9306 (commercially rated as resistant) and Pioneer Variety 9363 (commercially rated as susceptible) had similar root lengths, vol- umes, average diameters, and surface areas when grown in noninfested soil. Infection with the pathogen resulted in a decrease in root length and surface area relative to the control plants, but it was not significantly different between Pioneer cultivars. This was not the case for average root diameter, which was significantly smaller for Pioneer Variety 9363 than for Pioneer Variety 9306 when grown in pathogen-infested soil in either the inner core or outer region of the pot. In addition, when the outer region of the pot was infested with the pathogen, Pioneer Variety 9363 had a significantly lower volume of roots than Pioneer Variety 9306. We did not observe any consistent response to inoculation among the 12 cultivars that was specific to their commercially designated SDS resistance rating.

Testing for cross-contamination in soil. When the outer region of the pot was infested with $F$. solani f. sp. glycines, there was little or no movement of the pathogen from the outer region of soil into the noninfested inner core. No F. solani f. sp. glycines colonies were observed in soil sampled from noninfested outer regions on either sampling date, indicating that the pathogen did not move from the infested inner core outward. No colonies of $F$. solani f. sp. glycines were detected in soil sampled from the noninfested control treatment (data not presented).

Verification of fungal movement in root systems. When the inner core soil was infested with the fungus and the outer region contained noninfested soil, $84.4 \%$ of the upper taproot and $6.7 \%$ of the lateral root sections were colonized by $F$. solani f. sp. glycines. When soil in the outer region was infested and the inner core contained noninfested soil, colonization occurred on $91.8 \%$ of the taproot and $82.3 \%$ of the lateral root sections. No root sections from the control treatment were colonized by $F$. solani f. sp. glycines. Colonization levels of lateral root sections in the treatment where the inner core was infested were not significantly different $(P \geq 0.05)$ from colonization levels of lateral roots in the noninfested control treatment. Levels of taproot colonization in the inner core and outer region inoculation treatments were not significantly different $(P \geq 0.05)$.

\section{DISCUSSION}

The use of the inoculum placement assay allowed us to differentially infect portions of the soybean root system and determine that the location of pathogen infection in roots affected both root characteristics and SDS foliar symptom severity. For some cultivars, infection of the taproot resulted in significantly greater reductions in several root characteristics and significantly higher AUDPC values than did infection of lateral roots. How the location of the pathogen in roots affects disease development is not clearly understood, but it appears that for some related cultivars, lateral root infection causes the root system to respond differently than taproot infection.

In this study, all root characteristics, except average root diameter, were significantly lower for infected plants than for healthy plants. Reductions in root length also have been reported after root infection with $F$. solani on citrus (4), pea (14), and soybean (19). These results support the conclusion that root systems change after pathogen infection, and that this change

Table 3. Effect of Fusarium solani f. sp. glycines inoculum placement on foliar and root symptom severity for 12 soybean cultivars

\begin{tabular}{|c|c|c|c|c|c|c|}
\hline \multirow[b]{2}{*}{ Soybean cultivar } & \multicolumn{3}{|c|}{ Foliar AUDPC ${ }^{\mathbf{a}, \mathbf{b}}$} & \multicolumn{3}{|c|}{ Root discoloration $(\%)^{\mathbf{b}, \mathbf{c}}$} \\
\hline & Inner core $^{d}$ & Outer region & $P>|t|^{e}$ & Inner core & Outer region & $P>|t|$ \\
\hline D370RR & 721.5 & 345.8 & 0.218 & 77 & 76 & 0.88 \\
\hline D355RR & 820.0 & 460.8 & 0.044 & 76 & 84 & 0.44 \\
\hline D308 & 890.0 & 448.5 & 0.094 & 74 & 76 & 0.83 \\
\hline D354RR/N & 851.0 & 415.3 & 0.061 & 79 & 79 & 0.97 \\
\hline 372 & 758.8 & 359.8 & 0.036 & 75 & 73 & 0.92 \\
\hline 3552RR & 908.3 & 527.2 & 0.056 & 76 & 84 & 0.46 \\
\hline 3556STS & 807.3 & 338.0 & 0.086 & 68 & 68 & 0.98 \\
\hline 92B91 & 691.3 & 339.3 & 0.083 & 77 & 73 & 0.55 \\
\hline 9306 & 614.0 & 424.3 & 0.172 & 85 & 83 & 0.75 \\
\hline 9363 & 761.5 & 461.9 & 0.046 & 83 & 83 & 0.69 \\
\hline 3687RR & 732.0 & 404.0 & 0.034 & 87 & 74 & 0.14 \\
\hline 3252 & 509.5 & 444.8 & 0.304 & 67 & 66 & 0.91 \\
\hline Mean & 755.4 & 414.1 & 0.174 & 77 & 77 & 0.91 \\
\hline Column LSD $(P \geq 0.05)^{\mathrm{f}}$ & 191.0 & n.s.g & & n.s. & 10 & \\
\hline
\end{tabular}

${ }^{a}$ Foliar ratings were converted to percentages, using the midpoint rule, and the foliar severity value for each rating category was used to calculate AUDPC using: $\mathrm{AUDPC}=\sum_{i=1}^{n-1}\left[\left(X_{i+1}+X_{i}\right) / 2\right]\left(t_{i+1}-t_{i}\right)$ in which $X_{i}=$ percent foliar symptom severity at the $i$ th observation, $t_{i}=$ time (days between ratings) at the $i$ th observation, and $n=$ total number of observations $(n=5)$.

${ }^{\mathrm{b}}$ Results represent a combination of two trials.

${ }^{\mathrm{c}}$ Root discoloration was rated visually as the percentage of root system showing discoloration.

${ }^{\mathrm{d}}$ Inner core $=$ pots with the inner 4-cm-diameter soil core infested with $F$. solani $\mathrm{f}$. sp. glycines, and outer region filled with noninfested soil; outer region $=$ pots with the outer region of soil infested, and the inner 4-cm-diameter core filled with noninfested soil.

${ }^{\mathrm{e}} P>|\mathrm{t}|$ value for testing the hypothesis that the inner core and outer region areas are different.

${ }^{\mathrm{f}} \mathrm{LSD}=$ Fisher's protected least significant difference.

g n.s. = not significant at $P \geq 0.05$. 
may play a role in disease development. Our correlation results indicate that root characteristics might have a role in SDS development. A significant negative correlation was observed between AUDPC and root length, surface area, and volume for all inoculated plants. To our knowledge, no previous studies have evaluated the effects of $F$. solani f. sp. glycines infection on root system characteristics such as surface area, length, volume, or average diameter; however, Rupe (24) reported a significant negative relationship between root mass and SDS foliar symptoms. Conversely, Scherm and Yang (28) reported "no close correlation" between disease severity of root systems and foliar disease severity. Additional research is needed to determine the correlation of SDS foliar symptoms with these root characteristics.

Our results verify that $F$. solani f. sp. glycines is able to spread from infected lateral roots inward to the taproot. This indicates that infection of the lateral roots may play a more important role in SDS development than previously thought. In contrast, SDS lesion expansion along the root was not always observed $(10,19)$. Burke (2) reported that $F$. solani f. sp. phaseoli (Burk.) Snyder \& Hans moved little from infected to noninfected parts of the roots or hypocotyls. Rupe (24) reported that root discoloration from $F$. solani $\mathrm{f}$. sp. glycines spread on the taproot and up into the stem from the point of inoculation.

In the preliminary inoculum placement assay, where the inoculum rate was $80 \mathrm{ml}$ of infested sorghum per $4.5 \mathrm{~kg}$ soil, we observed discoloration of roots grown in the treatment with noninfested ground sorghum in the outer region, indicating that the presence of sorghum alone was able to discolor the roots. Lowering the infested sorghum level to $40 \mathrm{ml}$ per $4.5 \mathrm{~kg}$ of soil eliminated this problem.

We observed little or no passive movement of $F$. solani f. sp. glycines from infested to noninfested areas of the pots during the experiment. The lack of passive propagule movement was confirmed by the

Table 4. Effect of Fusarium solani f. sp. glycines inoculum placement on root length and surface area of 12 soybean cultivars

\begin{tabular}{|c|c|c|c|c|c|c|c|c|}
\hline \multirow[b]{3}{*}{ Soybean cultivar } & \multicolumn{8}{|c|}{ Root characteristics $^{\mathrm{a}}$} \\
\hline & \multicolumn{4}{|c|}{ Length (cm) } & \multicolumn{4}{|c|}{ Surface area $\left(\mathrm{cm}^{2}\right)$} \\
\hline & Control $^{b}$ & Inner core & Outer region & $P>|t|^{c}$ & Control & Inner core & Outer region & $P>|t|$ \\
\hline D370RR & $1,469.8^{c}$ & 180.1 & 314.9 & 0.41 & 224.6 & 24.9 & 42.8 & 0.42 \\
\hline D355RR & $1,608.6$ & 116.7 & 202.4 & 0.56 & 266.4 & 18.5 & 32.4 & 0.67 \\
\hline D308 & $1,378.1$ & 142.3 & 339.3 & 0.24 & 222.4 & 20.5 & 48.7 & 0.16 \\
\hline D354RR/N & $1,467.2$ & 124.3 & 277.0 & 0.22 & 212.2 & 17.5 & 36.9 & 0.25 \\
\hline 372 & $1,513.0$ & 136.5 & 344.3 & 0.12 & 244.5 & 20.5 & 49.3 & 0.18 \\
\hline 3552RR & $1,270.5$ & 99.2 & 181.3 & 0.38 & 199.5 & 16.5 & 28.4 & 0.42 \\
\hline 3556STS & $1,519.9$ & 192.3 & 348.1 & 0.30 & 243.0 & 27.1 & 49.6 & 0.36 \\
\hline $92 \mathrm{~B} 91$ & $1,492.8$ & 157.4 & 302.8 & 0.36 & 223.5 & 21.7 & 42.7 & 0.38 \\
\hline 9306 & $1,468.7$ & 119.7 & 252.9 & 0.33 & 229.1 & 18.0 & 39.5 & 0.23 \\
\hline 9363 & $1,424.6$ & 133.8 & 225.9 & 0.30 & 215.5 & 18.1 & 31.2 & 0.36 \\
\hline 3687RR & $1,425.5$ & 106.4 & 308.7 & 0.38 & 218.0 & 16.3 & 45.3 & 0.35 \\
\hline 3252 & $1,554.1$ & 240.7 & 301.2 & 0.64 & 246.7 & 31.0 & 41.7 & 0.59 \\
\hline Mean & $1,466.1$ & 145.8 & 283.2 & 0.002 & 228.8 & 20.9 & 40.7 & 0.002 \\
\hline $\operatorname{LSD}(P \geq 0.05)^{\mathrm{d}}$ & n.s..$^{\mathrm{e}}$ & 60.3 & 107.8 & & n.s. & 8.8 & 14.1 & \\
\hline
\end{tabular}

a Results represent the combination of two trials.

${ }^{\mathrm{b}}$ Control $=$ pots filled with noninfested soil; inner core $=$ pots with the inner 4-cm-diameter soil core infested with $F$. solani f. sp. glycines, and outer region filled with noninfested soil; outer region = pots with the outer region of soil infested, and the inner 4-cm-diameter core filled with noninfested soil.

${ }^{c} P>|\mathrm{t}|$ value represents the significance between the two inoculated treatments. Root characteristics for control plants were significantly greater than for plants in the two infested treatments.

${ }^{\mathrm{d}} \mathrm{LSD}=$ Fisher's protected least significant difference.

e n.s. $=$ not significant at $P \geq 0.05$.

Table 5. Effect of Fusarium solani f. sp. glycines inoculum placement on average root diameter and volume of 12 soybean cultivars

\begin{tabular}{|c|c|c|c|c|c|c|c|c|}
\hline \multirow[b]{3}{*}{ Soybean cultivar } & \multicolumn{8}{|c|}{ Root characteristics $^{\mathrm{a}}$} \\
\hline & \multicolumn{4}{|c|}{ Average diameter $(\mathrm{mm})$} & \multicolumn{4}{|c|}{ Volume $\left(\mathrm{cm}^{3}\right)$} \\
\hline & Control $^{\mathrm{b}}$ & Inner core & Outer region & $P>|t|^{c}$ & Control & Inner core & Outer region & $P>|t|$ \\
\hline D370RR & $0.49^{\mathrm{c}}$ & 0.49 & 0.43 & 0.16 & 2.76 & 0.28 & 0.46 & 0.55 \\
\hline D355RR & 0.52 & 0.52 & 0.52 & 0.95 & 3.53 & 0.24 & 0.42 & 0.75 \\
\hline D308 & 0.51 & 0.47 & 0.46 & 0.84 & 2.89 & 0.24 & 0.56 & 0.26 \\
\hline D354RR/N & 0.46 & 0.45 & 0.43 & 0.57 & 2.45 & 0.20 & 0.40 & 0.29 \\
\hline 372 & 0.51 & 0.48 & 0.47 & 0.43 & 3.15 & 0.25 & 0.57 & 0.28 \\
\hline 3552RR & 0.50 & 0.54 & 0.51 & 0.29 & 2.50 & 0.22 & 0.36 & 0.48 \\
\hline 3556STS & 0.51 & 0.46 & 0.47 & 0.81 & 3.11 & 0.31 & 0.57 & 0.45 \\
\hline 92B91 & 0.48 & 0.48 & 0.47 & 0.82 & 2.67 & 0.24 & 0.48 & 0.41 \\
\hline 9306 & 0.50 & 0.54 & 0.50 & 0.44 & 2.85 & 0.22 & 0.50 & 0.17 \\
\hline 9363 & 0.48 & 0.44 & 0.44 & 0.70 & 2.61 & 0.20 & 0.34 & 0.46 \\
\hline 3687RR & 0.49 & 0.49 & 0.48 & 0.64 & 2.66 & 0.20 & 0.53 & 0.32 \\
\hline 3252 & 0.51 & 0.42 & 0.45 & 0.43 & 3.14 & 0.32 & 0.46 & 0.65 \\
\hline Mean & 0.50 & 0.48 & 0.47 & 0.39 & 2.86 & 0.24 & 0.47 & 0.002 \\
\hline $\operatorname{LSD}(P \geq 0.05)^{\mathrm{d}}$ & 0.03 & 0.06 & 0.04 & & 0.63 & n.s. ${ }^{\mathrm{e}}$ & 0.15 & \\
\hline
\end{tabular}

${ }^{\text {a }}$ Results represent the combination of two trials.

${ }^{\mathrm{b}}$ Control = pots filled with noninfested soil; inner core = pots with the inner 4-cm-diameter soil core infested with F. solani f. sp. glycines, and outer region filled with noninfested soil; outer region = pots with the outer region of soil infested, and the inner 4-cm-diameter core filled with noninfested soil.

${ }^{c} P>|t|$ value represents the significance between the two inoculated treatments. Root characteristics for control plants were significantly greater than for plants in the two infested treatments.

${ }^{\mathrm{d}}$ LSD $=$ Fisher's protected least significant difference.

${ }^{\mathrm{e}}$ n.s. = not significant at $P \geq 0.05$. 
soil isolation assay. We did not include plants in this study because we wanted to verify that there was no passive movement of propagules through the soil. If roots were present, movement of the pathogen could have been the result of growth on or within the root tissue. Similarly, Burke (2) found no spread of $F$. solani f. sp. phaseoli through soil as a result of capillary movement of water. Pathogen spread with water was mainly due to washing over the soil surface. In this study, propagule movement in this manner was prevented by placing a layer of pasteurized, noninfested soil over the layer of infested soil in each pot.

A significant positive correlation between AUDPC and percent root discoloration was observed only when the initial site of infection was on the lateral roots. Therefore, the location of pathogen infection could be important when attempting to correlate root responses to foliar symptoms, especially if inoculation results in a higher percentage of taproot infection. Based on our results, we agree with the conclusions of Njiti et al. (20) that root rot severity should be used in combination with foliar disease severity as an indication of host resistance or disease development. This would be especially important when developing methods of screening for resistance to SDS. In order to accomplish this, the screening assay must be able to differentiate among cultivars based on root rot severity ratings. In this study, significant differences among soybean cultivars for root discoloration were observed only when lateral roots were inoculated; infecting the taproot to observe differences among cultivars for foliar symptom severity did not result in differences in root discoloration. Gray and Achenbach (5) were able to detect varying amounts of root rot severity caused by different SDS fungal isolates when they uniformly infested soil, which resulted in equal infection of both the taproot and lateral roots. Additional information about root system responses to SDS may be obtained when entire root systems are infected as opposed to only the taproot.

Based on our results, we determined that root system characteristics could be affected by the location of infection on the root system, and that useful information about root system responses to SDS may be obtained from inoculation of the entire root system as opposed to only taproot inoculation. The use of one $F$. solani $\mathrm{f}$. sp. glycines isolate in this study is a limitation that needs to be addressed with additional research. Variation among isolates of this pathogen is very common (23), and it is possible that different results could have been obtained if additional isolates were used. This study was evaluated under greenhouse conditions using a steampasteurized soil mix. Future research should assess root characteristics and location of infection under field conditions to observe whether the presence of indigenous microorganisms might alter the relationship between the taproot and lateral root infection and SDS development.

\section{ACKNOWLEDGMENTS}

This research was supported in part by the Illinois Soybean Program Operating Board and the UIUC Campus Research Board. We thank Garst Seed Company, Lewis Hybrids, Inc., Trisler Seed Farms, Inc., and Pioneer Hi-Bred International, Inc. for supplying seed. We thank Wayne Pedersen for his project advice and manuscript review, Danny Erickson for the use of the Reitz Desintegrator, Ruth Green and all the greenhouse staff, and the many students who made this research possible.

\section{LITERATURE CITED}

1. Aoki, T., O'Donnell, K., Homma, Y., and Lattanzi, A. 2003. Sudden-death syndrome of soybean is caused by two morphologically and phylogenetically distinct species within the Fusarium solani species complex-F. virguliforme in North America and F. tucumaniae in South America. Mycologia 95:660-684.

2. Burke, D. W. 1965. The near immobility of Fusarium solani f. phaseoli in natural soils. Phytopathology 55:1188-1190.

3. Campbell, C. L., and Madden, L. V. 1990. Introduction to Plant Disease Epidemiology. John Wiley \& Sons, Inc., New York

4. Dandurand, L. M., and Menge, J. A. 1993. Influence of Fusarium solani on citrus root growth and population dynamics of Phytophthora parasitica and Phytophthora citrophthora. Phytopathology 83:767-771.

5. Gray, L. E., and Achenbach, L. A. 1996. Severity of foliar symptoms and root and crown rot of soybean inoculated with various isolates and inoculum rates of Fusarium solani. Plant Dis. 80:1197-1199.

6. Hartman, G. L., Gardner, M. E., Hymowitz, T., and Naidoo, G. C. 2000. Evaluation of perennial Glycine species for resistance to soybean fungal pathogens that cause sclerotinia stem rot and sudden death syndrome. Crop Sci. 40:545-549.

7. Hartman, G. L., Huang, Y. H., Nelson, R. L., and Noel, G. R. 1997. Germplasm evaluation of Glycine max for resistance to Fusarium solani, the causal organism of sudden death syndrome. Plant Dis. 81:515-518.

8. Hershman, D. E., Hendrix, J. W., Stuckey, R. E., Bachi, P. R., and Henson, G. 1990. Influence of planting date and cultivar on soybean sudden death syndrome in Kentucky. Plant Dis. 74:761-766.

9. Hirrel, M. C. 1986. Sudden death syndrome of soybean: New insights into its development. Pages 95-104 in: Proc. Soybean Seed Conf. Am. Seed Trade Assoc. 16th.

10. Huang, Y. H., and Hartman, G. L. 1998. Reaction of selected soybean genotypes to isolates of Fusarium solani f. sp. glycines and their culture filtrates. Plant Dis. 82:999-1002.

11. Jin, H., Hartman, G. L., Nickell, C. D., and Widholm, J. M. 1996. Phytotoxicity of culture filtrate from Fusarium solani, the causal agent of sudden death syndrome of soybean. Plant Dis. 80:922-927.

12. Jin, H., Hartman, G. L., Huang, Y. H., Nickell, C. D., and Widholm, J. M. 1996. Regeneration of soybean plants from embryogenic suspension cultures treated with toxic culture filtrate of Fusarium solani and screening of regenerants for resistance. Phytopathology 86:714718.

13. Killebrew, J. F., Roy, K. W., Lawrence, G. W., McLean, K. S., and Hodges, H. H. 1988. Greenhouse and field evaluation of Fusarium solani pathogenicity to soybean seedlings. Plant Dis. 72:1067-1070.

14. Kraft, J. M., and Boge, W. 2001. Root charac- teristics in pea in relation to compaction and Fusarium root rot. Plant Dis. 85:936-940.

15. Lim, S. M. 1991. A technique for inoculating soybeans in the greenhouse with Fusarium solani. (Abstr.) Phytopathology 81:1238.

16. Luo, Y., Myers, O., Lightfoot, D. A., and Schmidt, M. E. 1999. Root colonization of soybean cultivars in the field by Fusarium solani f. sp. glycines. Plant Dis. 83:1155-1159.

17. Melgar, J., and Roy, K. W. 1994. Soybean sudden death syndrome: Cultivar reactions to inoculations in a controlled environment and host range and virulence of causal agent. Plant Dis. 78:265-268.

18. Mitchell, R. L., and Russell, W. J. 1971. Root development and rooting patterns of soybean (Glycine $\max (\mathrm{L}$.) Merrill) evaluated under field conditions. Agron. J. 63:313-316.

19. Mueller, D. S. 2001. Resistance to Fusarium solani $\mathrm{f}$. sp. glycines, the causal organism of sudden death syndrome of soybean. Ph.D. diss. University of Illinois, Urbana-Champaign.

20. Njiti, V. N., Suttner, R. J., Gray, L. E., Gibson, P. T., and Lightfoot, D. A. 1997. Rate-reducing resistance to Fusarium solani f. sp. phaseoli underlies field resistance to soybean sudden death syndrome. Crop Sci. 37:132-138.

21. Ortiz-Ribbing, L. M., and Eastburn, D. M. 2003. Evaluation of digital image acquisition methods for determining soybean root characteristics. Online. Crop Management doi:10.1094/CM-2003-0702-01-RS.

22. Roy, K. W. 1997. Fusarium solani on soybean roots: Nomenclature of the causal agent of sudden death syndrome and identity and relevance of $F$. solani form B. Plant Dis. 81:259266.

23. Roy, K. W., Rupe, J. C., Hershman, D. E., and Abney, T. S. 1997. Sudden death syndrome of soybean. Plant Dis. 81:1100-1111.

24. Rupe, J. C. 1989. Frequency and pathogenicity of Fusarium solani recovered from soybeans with sudden death syndrome. Plant Dis. 73:581-584.

25. Rupe, J. C., and Gbur, E. E., Jr. 1995. Effect of plant age, maturity group, and the environment on disease progress of sudden death syndrome of soybean. Plant Dis. 79:139-143.

26. Rupe, J. C., Gbur, E. E., and Marx, D. M. 1991. Cultivar responses to sudden death syndrome of soybean. Plant Dis. 75:47-50.

27. Rupe, J. C., Robbins, R. T., Becton, C. M., Sabbe, W. A., and Gbur, E. E., Jr. 1999. Vertical and temporal distribution of Fusarium solani and Heterodera glycines in fields with sudden death syndrome of soybean. Soil Biol. Biochem. 31:245-251.

28. Scherm, H., and Yang, X. B. 1996. Development of sudden death syndrome of soybean in relation to soil temperature and soil water matric potential. Phytopathology 86:642-649.

29. Stephens, P. A., Nickell, C. D., and Kolb, F. L. 1993. Genetic analysis of resistance to Fusarium solani in soybean. Crop Sci. 33:929-930.

30. Stephens, P. A., Nickell, C. D., and Lim, S. M. 1993. Sudden death syndrome development in soybean cultivars differing in resistance to Fusarium solani. Crop Sci. 33:63-66.

31. Stephens, P. A., Nickell, C. D., Moots, C. K., and Lim, S. M. 1993. Relationship between field and greenhouse reactions of soybean to Fusarium solani. Plant Dis. 77:163-166.

32. Tennant, D. 1975. A test of the modified line intersect method for estimating root length. J. Ecol. 63:995-1001.

33. Tooley, P. W., and Grau, C. R. 1984. Field characterization of rate-reducing resistance to Phytophthora megasperma f. sp. glycinea in soybean. Phytopathology 74:1201-1208.

34. Wrather, J. A., Kendig, S. R., Anand, S. C., Niblack, T. L., and Smith, G. S. 1995. Effects of tillage, cultivar, and planting date on percentage of soybean leaves with symptoms of sudden death syndrome. Plant Dis. 79:560-562. 